\title{
LIV. On the changes produced in the molecular condition of iron by heating to redness and cooling
}

\section{Carl Fromme}

To cite this article: Carl Fromme (1884) LIV. On the changes produced in the molecular condition of iron by heating to redness and cooling , Philosophical Magazine Series 5, 18:115, 473-485, DOI: $10.1080 / 14786448408627626$

To link to this article: http://dx.doi.org/10.1080/14786448408627626

曲 Published online: 29 Apr 2009.

Submit your article to this journal $[\pi$

Џ Article views: 2

Q View related articles $\square$ 
LONDON, EDINBURGH, AND DUBLIN

\title{
PHILOSOPHICAL MAGAZINE
}

\author{
$\triangle N D$ \\ JOURNAL OF SCIENCE.
}

[FIFTH SERIES.]

$D E C E M B E R 1884$.

IIV. On the Changes produced in the Molecular Condition of Iron by Heating to Redness and Cooling. By $\mathrm{CARL}_{\mathrm{H}}$ FoMme*.

GOME years ago, upon the publication of some magnetic $\checkmark$ experimentst, I made a short communication upon the change in density which steel undergoes upon hardening, and subsequently added to the fuller description $\ddagger$ of the same experiments, in these Annalen, a series of observations made to determine the distribution of density in the interior of a hardened steel bar. The general applicability of one of the former results has recently been called in question by observations of $\mathrm{H}$. Meyer\$. These observations show an increase in density upon hardening for one ("drawn soft bright steel") of three kinds of steel examined, whilst the other two kinds ("best bright English cast steel" and "polished English steel") showed the decrease which alone I had observed\|. I have therefore made new experiments upon these phenomena of change of density upon hardening, and endeavoured to obtain a nearer insight into the reasons of these phenomena by extending the observations to the different modifications of iron, from pure electrolytic iron free from carbon to the more highly carbonaceous cast iron.

The question of the distribution of density in a hardened steel bar had been far from solved by the single series of obser-

* Translated from Wiedemann's Annalen, No. 7 (1884).

$\dagger$ Gött. Nachr. 1876, pp. 157-168.

t Wied. Ann. viii. pp. 352-356 (1879); Phil. Mag. [5] viii. p. 421 (1879).

\$ H. Meyer, Wied. Ann. xviii. p. 233 (1883).

Il There is an older observation of Rinmann (in his Geschichte des Eisens, German translation by Karsten), according to which Styrian steel experienced an increase in density of from 7.782 to $7 \cdot 822$ upon hardening.

Plil. Mag. S. 5. Vol. 18. No.115. Dec.1884. 2 I 


\section{M. Fromme on the Changes produced in the Molecular}

vations which I had published; on the contrary, their result had been so remarkable and unexpected that further experiments were much to be desired. Since I have not in the mean time become acquainted with investigations on this subject, I offer now a small contribution to the solution of the question.

\section{On the Change in Density produced by Tempering Iron.}

The following materials were employed :-

(a) Iron wire 1.4 millim. thick.

(b) Iron wire 0.5 millim. thick, obtained by drawing out the wire $(a)$.

(c) Iron wire $0.3 \mathrm{millim}$. thick.

(d) Steel wire 0.7 millim. thick.

(e) Steel wire 0.4 millim. thick. $(d)$ and $(e)$ were from the same works in Birmingham, and were called "patent steel music-wire."

(f) Cylindrical steel rod 5.5 millim. thick, 30 millim. long.

(g) Electrolytic iron in small pieces, deposited from a solution of ferrous sulphate. Thickness about 0.1 millim.

(h) Electrolytic iron deposited from a solution of ferric chloride. Three small pieces were cut from a large piece and tested separately. Mean thickness of the large piece $0 \cdot 14$ millim.

(i) Cast iron in the form of a cylinder, 18 millim. long and 7 millim. thick.

(k) Cast iron in the form of a plate (20:10:5 millim.).

(l) Wrought iron in the form of a cylinder 25 millim. long and $5 \cdot 6$ millim. thick.

(m) White pig-iron in small pieces, such as could be obtained from a larger piece by breaking it up with a hammer.

For determination of density, a Geissler's pycnometer was employed, except for $(h)$ and $(k)$, the densities of which were determined with the hydrostatic balance. The metal was heated in the flame of the Bunsen burner or in the blowpipe-flame.

When slow cooling was desired the pieces of metal were allowed to cool in the bright flame and above it, whilst rapid cooling was attained by plunging the hot body into water of $10^{\circ}$ or $15^{\circ}$. The coating of oxide was removed before each determination. The wires were examined by cutting off pieces suitable to the height of the vessel of the pycnometer, of about 4 centim. long, and testing a number together (thirty in the case of the thinnest wires).

Fach specimen was first heated and cooled slowly, and then its density $\delta_{l}$ measured; then it was heated again and cooled rapidly, and its density $\delta_{r}$ determined. Thus determinations of $\delta_{l}$ and $\delta_{r}$ alternated with each other, often repeatedly. Table I. exhibits ali the observations brought together. 
Condition of Iron by Heating to Redness and Cooling. 475

Table I.

\begin{tabular}{|c|c|c|c|c|c|}
\hline $\begin{array}{l}\text { Designation } \\
\text { of material. }\end{array}$ & $\begin{array}{c}\text { Slowly } \\
\text { cooled. } \\
\delta l .\end{array}$ & $\begin{array}{c}\text { Rapidly } \\
\text { cooled. } \\
\delta \%\end{array}$ & \multicolumn{2}{|c|}{$\delta_{*}-\delta z_{.}$} & $\begin{array}{l}\delta_{y}-\delta l \\
\text { Mean. }\end{array}$ \\
\hline$a \ldots$. & $\begin{array}{r}7 \cdot 4772 \\
45 \% 2 \\
4495 \\
4384\end{array}$ & $\begin{array}{r}7 \cdot 4642 \\
4572 \\
4554 \\
4367\end{array}$ & $\begin{array}{l}-0.0005 \\
+0.0084 \\
+0.0068 \\
+0.0068\end{array}$ & $\begin{array}{c}+00115 \\
+00076 \\
\ldots \ldots \\
\ldots \ldots\end{array}$ & +0.007 \\
\hline$b \ldots \ldots$ & $\begin{array}{r}7 \cdot 2830 \\
2370 \\
2064 \\
1925\end{array}$ & $\begin{array}{r}7 \cdot 2585 \\
1937 \\
1977 \\
1587\end{array}$ & $\begin{array}{l}-0.0015 \\
-0.0109 \\
-0.0280 \\
-0.0107\end{array}$ & $\begin{array}{c}-0.0017 \\
-0.0149 \\
\ldots . . . \\
\ldots . . .\end{array}$ & $-0 \cdot 011$ \\
\hline$c \ldots . .$. & $\begin{array}{r}7 \cdot 7585 \\
7319 \\
7022\end{array}$ & $\begin{array}{r}7 \cdot 7549 \\
7449 \\
7237\end{array}$ & $\begin{array}{l}+0.0097 \\
+0.0180 \\
+0.0279\end{array}$ & $\begin{array}{c}+0.0321 \\
\ldots \ldots \\
\ldots \ldots\end{array}$ & +0.022 \\
\hline $\left.\begin{array}{c}c \ldots \ldots . . . \\
\text { (a second } \\
\text { wire) }\end{array}\right\}$ & $\begin{array}{r}7 \cdot 7571 \\
7422 \\
7240\end{array}$ & $\begin{array}{r}7 \cdot 7794 \\
7879 \\
7534\end{array}$ & $\begin{array}{l}+0.0298 \\
+0.0414 \\
+00548\end{array}$ & $\begin{array}{c}+0.0466 \\
\ldots \ldots \\
\ldots \ldots .\end{array}$ & $+0 \cdot 043$ \\
\hline$d \ldots . .$. & $\begin{array}{r}7 \cdot 7954 \\
7754\end{array}$ & $\begin{array}{r}77240 \\
6874\end{array}$ & $\begin{array}{l}-0.0614 \\
-0.0697\end{array}$ & ….. & -0.066 \\
\hline & $\begin{array}{r}7 \cdot 7742 \\
7602\end{array}$ & $\begin{array}{r}7 \cdot 7119 \\
6834\end{array}$ & $\begin{array}{l}-0.0553 \\
-0.0626\end{array}$ & ….. & -0.059 \\
\hline$f \ldots \ldots$ & 7.7970 & $7 \cdot 7210$ & -0.0760 & ...... & -0.076 \\
\hline$g \ldots$ & $7 \cdot 5682$ & $7 \cdot 5689$ & +0.0007 & ...... & $+0 \cdot 001$ \\
\hline$h_{1} \ldots \ldots$ & $\begin{array}{r}7.6574 \\
6669 \\
6714\end{array}$ & $\begin{array}{r}7 \cdot 6334 \\
6334 \\
6656 \\
6892\end{array}$ & $\begin{array}{r}-0.0240 \\
0.0287 \\
-0.0174 \\
-0.0035\end{array}$ & $\begin{array}{c}+0.0060 \\
\ldots \ldots \\
\ldots \ldots \\
\ldots \ldots\end{array}$ & $-0 \cdot 013$ \\
\hline$h_{2} \ldots$ & $\begin{array}{r}7.7026 \\
6960 \\
7020\end{array}$ & $\begin{array}{r}7 \cdot 6927 \\
6912 \\
7044 \\
6888\end{array}$ & $\begin{array}{r}-0.0107 \\
-0.0081 \\
+0.0018 \\
+0.0054\end{array}$ & $\begin{array}{c}-0.0054 \\
\ldots \ldots \\
\ldots . . \\
\ldots . .\end{array}$ & -0.003 \\
\hline$h_{3} .$. & $\begin{array}{r}77110 \\
6937 \\
6989\end{array}$ & $\begin{array}{r}7 \cdot 7047 \\
6867 \\
7072 \\
6978\end{array}$ & $\begin{array}{r}-0.0153 \\
-0.0156 \\
+0.0032 \\
+0.0109\end{array}$ & $\begin{array}{c}+0.0036 \\
\ldots \ldots \\
\ldots \ldots \\
\ldots \ldots\end{array}$ & -0.003 \\
\hline$i \ldots$ & $\begin{array}{l}7 \cdot 0412 \\
7 \cdot 0152 \\
6.9989\end{array}$ & $\begin{array}{l}7 \cdot 0137 \\
7 \cdot 0052 \\
6.9919\end{array}$ & $\begin{array}{l}-0.0145 \\
-0.0058 \\
-0.0018\end{array}$ & $\begin{array}{c}-0.0001 \\
\ldots \ldots \\
\ldots \ldots\end{array}$ & -0.000 \\
\hline & $\begin{array}{r}7 \cdot 1465 \\
1402 \\
1345 \\
1266 \\
1097 \\
1024 \\
0986 \\
0915\end{array}$ & $\begin{array}{r}7 \cdot 1384 \\
1319 \\
1297 \\
1004 \\
1029 \\
1042 \\
0887 \\
0906\end{array}$ & $\begin{array}{l}-0.0049 \\
-0.0051 \\
-0.0054 \\
-0.0037 \\
-0.0008 \\
-0.0116 \\
-0.0117 \\
-0.0081\end{array}$ & $\begin{array}{c}-0.0031 \\
+0.0011 \\
+0.0037 \\
-0.0029 \\
-0.0063 \\
-0.0019 \\
\ldots \ldots . \\
\ldots . . .\end{array}$ & -0.005 \\
\hline$l \ldots . . .\{\{$ & $\begin{array}{r}7 \cdot 6564 \\
6444\end{array}$ & $\begin{array}{r}7 \cdot 6530 \\
6344\end{array}$ & $\begin{array}{l}+0.0026 \\
-0.0007\end{array}$ & $\ldots . .$. & +0.001 \\
\hline$m \ldots . .$. & $\begin{array}{r}7 \cdot 6320 \\
5915\end{array}$ & $\begin{array}{r}7 \cdot 5539 \\
5209\end{array}$ & $\begin{array}{l}-0.0578 \\
-0.0541\end{array}$ & $\begin{array}{l}\ldots . . . \\
\ldots \ldots .\end{array}$ & -0.056 \\
\hline $\begin{array}{c}m \ldots \ldots . . \\
\text { (other } \\
\text { pieces) }\end{array}$ & $\begin{array}{r}7.5754 \\
5510\end{array}$ & $\begin{array}{r}7 \cdot 5097 \\
4805\end{array}$ & $\begin{array}{l}-0.0535 \\
-0.0559\end{array}$ & $\begin{array}{l}\ldots \ldots \\
\ldots \ldots\end{array}$ & $-0-055$ \\
\hline
\end{tabular}


The first point which strikes the eye upon examining this table is the decrease, often considerable, which is produced by repeated heating, in the density of all the kinds of iron, with the single exception of electrolytic iron.

The exception, presented by pure iron only*, suggests the cause of the phenomenon; it evidently is to be sought in the varying proportion of carbon contained in the material which will suffer change upon ignition. The total percentage of carbon may vary, as well as the proportion between combined carbon and graphite. It may be noted that none of the pieces were heated longer than necessary. The smallest value of the density is then often not reached after repeatedly heating. This continuous decrease in density made it necessary to combine the determinations suitably, before the question proposed as to the difference in density caused by rapid cooling and slow cooling could be answered. I have combined each measurement with that preceding and that following it, and thus obtained the numbers contained in the fourth column of Table I. The intermediate members of the series $\delta_{l}$ and $\delta_{r}$ have, however, more share in the formation of these differences than the terminal numbers. Nevertheless I have taken the simple arithmetical mean of all the differences to three places of decimals, since it does not depend upon a knowledge of the exact values of $\delta_{r}-\delta_{l}$.

If we now compare with each other the mean values contained in the last column, we find an increase in specific gravity upon rapid cooling only with the iron wires $a$ and $c$, the electrolytic iron $g$, and the wrought iron $l$. We have, however, only one measurement of the electrolytic iron $g$, and the difference resulting from it lies within the limit of experimental error. For the wronght iron $l$ we have two differential values; but they are of small magnitude and of different sign. Hence we may conclude that with the electrolytic iron $(g)$ and with the wrought iron $(l)$ the density is sensibly independent of the velocity with which the heated substance cools.

On the other hand, an increase in specific gravity after tempering is distinetly observed with the iron wires $(a)$ and $(c)$, and with the wires (e) it is even considerable.

All the other substances examined-that is to say, the iron wires, the steel wires $(d)$ and $(e)$, the steel bar $(f)$, the electrolytic iron $(h)$, the cast iron (grey pig-iron) $(i)$ and $(k)$, and, lastly, the white pig-iron $(m)$-all suffered a decrease in specific

* With the piece $h_{1}$, on the contrary, the specific gravity increased upon repeated heating. To begin with, it was decidedly smaller than that of the other two pieces, but upon repeated heating became continually more nearly the same. 
gravity upon tempering. This decrease is the greatest in the case of steel and white cast iron, smaller with the iron wire (c), and smallest with the cast iron and the electrolytic iron. But whilst this decrease in density is beyond doubt with all the kinds of steel examined, the iron wire, and the grey and white pig-iron, the mean values found for the electrolytic iron must be received with caution; since, of the whole fifteen values of $\delta_{r}-\delta_{l}$, nine are positive and six negative. Hence I consider it not improbable that a larger number of measurements (which was not possible on account of the gradual diminution in the size of the piece) would give a mean value approaching zero. I therefore regard the existence of a difference in density of electrolytic iron, after slow cooling or rapid cooling, as not proved. The different varieties of iron are classified, as we know, according to the quantity of carbon they contain, which may be present either in the free condition or chemically combined; for the percentage of carbon determines, if not exclusively yet to a great extent, the properties of any particular kind of iron. Hence I had no doubt that both the sign and magnitude of the change in density produced by tempering would be dependent upon the percentage of carbon. The observations indeed do not contradict this assumption, but they by no means determine the law of the connexion. It results from the measurements made with cast iron and with white pig-iron, that the change in density depends less upon the total percentage of carbon than upon the quantity of chemically combined carbon. For in the case of white pig-iron containing much combined carbon, the change was ten times as great as with grey pig-iron, in which the carbon was contained chiefly as graphite.

Whilst with white pig-iron and steel (substances containing the largest percentage of combined carbon) the density diminished upon tempering, it increased with the three linds of iron wire examined-substances which contained only a small percentage of combined carbon. The third kind of iron wire, obtained by drawing down one of the first two kinds, behaved in the opposite way; which may possibly be explained by a change of free carbon into combined carbon, caused by the operation of drawing. If so, smaller quantities of chemically combined carbon in iron produce an increase in density, and larger quantities a decrease, when the red-hot wire is plunged into cold water.

This assumption does not appear to be negatived by the two observations, which alone, so far as I know, have shown an increase in density of steel upon tempering. For, according to a table given in Scheerer's Metallurgie, Styrian stoe], 
with which Rinmann experimented, contains only a small quantity of carbon; and the designation of the steel examined by H. Meyer as "soft" also points to a small percentage of carbon.

Whether the view which I have expressed, chiefly by way of surmise, is correct or not must be decided by more extended experiments, accompanied by analysis of the kinds of iron examined.

Mousson, in his Lehrbuch der Physik, has endeavoured to explain the change in density produced by tempering as purely mechanical, assuming that the initial cooling of the exterior prevents the interior portions from contracting, as they otherwise would do upon the fall of temperature. Hence the exterior layers are left in a condition of forcible compression, and the interior in a condition of forcible extension. Hence, according to Mousson, three things would follow :-first, an increased density and hardness of the superficial layers; secondly, a diminished density and hardness of the interior; and, thirdly, an increase in volume.

Let us for the present disregard the first two, and concern ourselves only with the third result.

This conclusion is in opposition to the results obtained with the iron wires $(a)$ and $(c)$, as well as the observations of Rinmann and Meyer. Any such purely mechanical explanation of the processes involved in tempering can certainly not be maintained. But, since Mousson's explanation takes no account of chemical changes during the process of tempering, and since it can be shown that such changes occur in iron containing carbon, it seemed possible that the above explanation might at least be applicable to pure iron; and in fact pure iron does exhibit on the whole an increase of volume upon tempering. Bot, as already pointed out, the mean values obtained cannot be considered decisive upon this point. I have further examined platinum, but did not succeed in showing any change in volume.

On this account I am of opinion that a change of volume, as a result of rapid cooling, only takes place with good conductors, such as the metals, if chemical changes occur at the same time. On the other hand, I do not at all deny the possibility of such changes with substances of small conductingpower for heat, such as glass.

2. On the Distribution of Density and Hardness in Tempered Steel.

I have made experiments upon the distribution of density and hardness only with one kind of steel, that marked $f$. 
Before describing these experiments, I wish to mention a few experiments made with other kinds of iron.

It is well known that no sharp distinction, depending only on percentage of carbon, can be drawn between wrought iron and steel. For the property of hardness characteristic of steel is dependent not only upon the quantity of carbon, but also upon the presence of traces of other metals; so that iron containing only about 0.5 per cent. of carbon, if it contains also other metals as impurities, may be hardened, and thus behaves like steel. Only when it contains still smaller quantities of carbon (less than 0.5 per cent.) can iron be indiscriminately characterized as soft iron, $i$. e. it acquires only slightly increased hardness by being suddenly cooled in cold water; and this increase is the less the smaller the percentage of carbon and other foreign substances. This is the usual view, and Karsten expresses himself to the same effect in his Handbuch der Eisentiüttenkunde, when he says, "It is characteristic of all kinds of bar-iron that their hardness is not perceptibly increased by being suddenly quenched in cold water."

My experiments entirely agree with this result : the varieties of iron wire $(b)$ and $(c)$ were found to be distinctly, but not considerably, harder after rapid cooling than when slowly cooled, since they offered more resistance to flexure. The hardness has therefore no connexion with the simultaneous change in density; since, whilst the density of $(b)$ decreased, that of $(c)$ increased. I was not able to obtain any definite result with the iron wire $(a)$ on account of its greater thickness. The electrolytic iron was certainly not made harder by sudden cooling. Lastly, I have tested the cast iron, as well as the brittle white pig-iron, with the file, but without any certain result.

Lastly must be mentioned that platinum and copper do not appear to become harder by sudden cooling than by slow cooling. It appears, then, that the property possessed by metals of being hardened is assaciated with the commencement of a chemical change. In the case of iron it is chiefly carbon, which, when it is present in certain quantities, neither too great nor too small, undergoes chemical change upon sudden cooling, and is thus the cause of the hardening which takes place.

Five pieces were cut from a cylindrical rod of steel of 0.55 centim. diameter. Four of these of the same length (about 3 centim.) were heated and cooled quickly, $(a)$ and $(b)$ in water of $45^{\circ},(c)$ and $(d)$ in water of $15^{\circ}$. The fifth piece (e) was only $2 \cdot 3$ centim. long. It was made red hot and allowed to cool gradually to the temperature of the room. After deter- 


\section{M. Fromme on the Changes produced in the Molecular}

mining the densities of the pieces, they were placed in nitric acid to which a little hydrochloric acid had been added, and were allowed to be acted upon to a certain extent; then the density was determined again; they were further acted upon by the acid; and so on.

The action took place, on the whole, very regularly: the bars retained their cylindrical form and smooth surface; two of the pieces showed channels, but of very small depth.

The hydrostatic balance was employed for the determination of density, except that the first ten observations with the bar (b) were made with the previously mentioned pycnometer. Table II. contains the results of the determination of density, together with the absolute weights of the pieces.

TABLE II.

\begin{tabular}{|c|c|c|c|c|c|c|c|c|c|c|}
\hline \multirow{2}{*}{$\begin{array}{l}\text { No. } \\
\text { of } \\
\text { obs. }\end{array}$} & \multicolumn{2}{|c|}{ a. } & \multicolumn{2}{|c|}{$b}$. & \multicolumn{2}{|c|}{$c$. } & \multicolumn{2}{|c|}{ d. } & \multicolumn{2}{|c|}{$e$. } \\
\hline & $m$ & $\delta$ & $m$ & $\delta$ & $m$ & $\delta$. & $m$. & $\delta$. & $m$ & $\delta$ \\
\hline 1. & $6 \cdot 635$ & $7 \cdot 735$ & 6.480 & $7 \cdot 714$ & $6: 328$ & 7715 & 6.338 & $7 \cdot 727$ & 4.931 & $7 \cdot 795$ \\
\hline 2. & 624 & 734 & 462 & 703 & 245 & 704 & 248 & 718 & 856 & 790 \\
\hline 3. & 610 & 731 & 452 & 754 & 204 & 706 & 122 & 718 & 777 & 789 \\
\hline 4. & 596 & 733 & 402 & 754 & 142 & 706 & 005 & 713 & 670 & 794 \\
\hline 5. & 576 & 799 & 360 & 760 & 051 & 704 & 5.892 & 716 & 577 & 793 \\
\hline 6. & 538 & 731 & 321 & 758 & $5 \cdot 946$ & 698 & 784 & 716 & 508 & 792 \\
\hline 7. & 495 & 731 & 282 & 759 & 803 & 702 & 625 & 723 & 437 & 798 \\
\hline 8. & 474 & 731 & 229 & 757 & 332 & 700 & 581 & 718 & 343 & 791 \\
\hline 9. & 424 & 730 & 188 & 753 & 181 & 704 & 377 & 716 & 270 & 798 \\
\hline 10. & 349 & 732 & 154 & 758 & $4 \cdot 868$ & 696 & 278 & 715 & 177 & 789 \\
\hline 11. & 296 & 733 & 115 & 745 & 594 & 708 & 145 & 714 & 103 & 788 \\
\hline 12. & 241 & 731 & 072 & 747 & 297 & 705 & 026 & 704 & 3.999 & 791 \\
\hline 13. & 080 & 728 & 016 & 745 & 060 & 701 & 4.909 & 708 & 861 & 790 \\
\hline 14. & 018 & 735 & 5.974 & 743 & 3778 & 697 & 772 & 704 & 771 & 787 \\
\hline 15. & 5754 & 730 & 916 & 747 & 535 & 698 & 607 & 710 & 656 & 783 \\
\hline 16. & 587 & 735 & 857 & 739 & 202 & 710 & 391 & 710 & 590 & 786 \\
\hline 17. & 129 & 725 & 813 & 733 & $2 \cdot 898$ & 693 & 201 & 714 & 507 & 781 \\
\hline 18. & $4 \cdot 630$ & 728 & 756 & 735 & $\ldots$ & $\ldots$ & 3.973 & 705 & 395 & 789 \\
\hline 19. & 177 & 731 & 696 & 736 & $\ldots$ & $\ldots$ & 759 & 705 & 318 & 792 \\
\hline 20. & 3.645 & 735 & 649 & 739 & $\ldots$ & $\ldots$ & 559 & 700 & 216 & 795 \\
\hline 21. & 038 & 734 & 590 & 737 & $\ldots$ & $\ldots$ & 388 & 720 & 116 & 792 \\
\hline 22 & 2747 & 733 & 527 & 736 & $\ldots$ & $\ldots$ & 237 & 715 & 2.987 & 794 \\
\hline 23. & $\ldots$ & $\ldots$ & 484 & 737 & $\ldots$ & $\ldots$ & 049 & 715 & 880 & 780 \\
\hline 24. & $\ldots$ & $\ldots$ & 435 & 736 & $\ldots$ & $\ldots$ & 2.882 & 708 & $\ldots$ & $\cdots$ \\
\hline 25. & $\ldots$ & $\ldots$ & 378 & 740 & $\ldots$ & $\ldots$ & 737 & 705 & $\ldots$ & $\ldots$ \\
\hline 26 & $\ldots$ & $\cdots$ & 321 & 737 & $\ldots$ & $\ldots$ & $\ldots$ & $\ldots$ & $\ldots$ & $\ldots$ \\
\hline 27 & $\cdots$ & $\cdots$ & 247 & 736 & $\cdots$ & $\ldots$ & $\cdots$ & 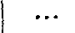 & 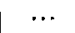 & 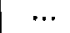 \\
\hline 28. & $\ldots$ & $\cdots$ & 176 & 735 & $\ldots$ & $\ldots$ & $\ldots$ & $\ldots$ & $\ldots$ & $\ldots$ \\
\hline 29. & $\cdots$ & $\cdots$ & 083 & 736 & $\ldots$ & $\ldots$ & $\ldots$ & $\cdots$ & $\ldots$ & $\cdots$ \\
\hline 30. & $\ldots$ & $\cdots$ & 4.998 & 734 & $\ldots$ & $\ldots$ & $\ldots$ & $\ldots$ & $\ldots$ & 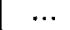 \\
\hline 31. & $\ldots$ & $\ldots$ & 660 & 735 & $\ldots$ & $\ldots$ & $\ldots$ & $\ldots$ & $\ldots$ & $\ldots$ \\
\hline
\end{tabular}

The density of the bar (a) thus remained nearly constant throughout the process of dissolving away. It was almost 
always somewhat smaller (at most by 0.007 ) than at first, and only reached the initial value three times, $i$. e. the mean density of the unattacked and newly tempered bar ; on the average it was smaller by 0.004 . With the bar $(b)$ the density at first diminished rapidly, then increased, and then gradually sank with small variations to a constant value, greater than the initial value.

With the other two bars $(c)$ and $(d)$, which were cooled in colder water, the density alternately diminished and increased, and the changes took place much in the same way, a maximum or minimum occurring about the same densities of the bar. In both eases the density remained lower than the initial value; on the average it was about 0.015 less.

of these four series of observations the second leads to very remarkable results. If we calculate the densities of the layers removed between the first and second observation, and between the second and third observation, we find the values to be 16 and 2. The thickness of each of the two layers would be about 0.002 millim.

Although, on account of the smallness of the quantities dissolved off, these numbers may be affected by errors of relatively large magnitude, yet, unless we suppose gross errors of observation to exist, which I do not consider to be probable, the fact remains that between an external dense layer and a central portion of nearly uniform density there existed a layer of extraordinarily small density. Apart from this peculiar condition of the surface, the distribution of density is quite regular-the density decreases until it reaches a constant value. Consequently we have a dense envelope enclosing a less dense kernel.

The first series of observations, which relate to a bar tempered in warm water, shows an extraordinarily small difference in density. The greatest difference between any two observations amounts to seven in the third decimal place, which may certainly be attributed to accidental want of homogeneity. From the fact that the density becomes less upon the whole, we may certainly conclude that this bar must have possessed a density decreasing, with small variations, from outside towards the interior.

The same conclusion follows from the measurements made with the two pieces $(c)$ and $(d)$, which were tempered in cold water. With them, however, the difference between the density of the exterior layer and the interior is much greater than with the bar (a), but the irregularities in the distribution of density are also much greater.

I have calculated the densities of the layers, dissolved away 
between two observations, giving a relative maximum or minimum. Table III. A contains the results of this calculation for the bar $(d)$, as well as the mean density of the layers dissolved off up to the observation in question, and the mean density of the portion left.

TABLE III. A.

\begin{tabular}{|c|c|c|c|}
\hline $\begin{array}{l}\text { Number of } \\
\text { observation. }\end{array}$ & $\begin{array}{c}\delta_{1} . \\
\text { Density of } \\
\text { layer removed } \\
\text { between two } \\
\text { observations. }\end{array}$ & $\begin{array}{l}\delta_{2} \\
\text { Density of the } \\
\text { portions removed } \\
\text { between the first } \\
\text { observation and } \\
\text { one of the subse- } \\
\text { quent ones. }\end{array}$ & $\begin{array}{c}\delta_{3} \\
\text { Density of the } \\
\text { part of the bar } \\
\text { unattacked. }\end{array}$ \\
\hline $\begin{array}{r}1 . \ldots . . \\
4 . \ldots \ldots \\
7 . \ldots \ldots \\
13 . \ldots \ldots \\
17 . \ldots \ldots \\
20 . \ldots . \\
21 . \ldots . \\
26 . \ldots . \\
\end{array}$ & $\begin{array}{l}7 \cdot 98 \\
7 \cdot 58 \\
7 \cdot 88 \\
7 \cdot 65 \\
7 \cdot 79 \\
7 \cdot 31 \\
7 \cdot 76\end{array}$ & $\begin{array}{l}7 \cdot 98 \\
7.76 \\
7 \cdot 82 \\
7 \cdot 75 \\
9.79 \\
7 \cdot 74 \\
7 \cdot 74\end{array}$ & $\begin{array}{l}7 \cdot 71 \\
7 \cdot 72 \\
7.70 \\
7.71 \\
7 \cdot 70 \\
7 \cdot 72 \\
7 \cdot 71\end{array}$ \\
\hline
\end{tabular}

The values of $\delta_{1}$ show that there are layers of greater and smaller density, alternating with each other; those of $\delta_{2}$ taken together with those of $\delta_{3}$ show that the density decreases from the outside towards the centre, since the density of the part dissolved away always exceeds that of the remaining portion.

The slowly cooled bar $(e)$ was examined to see if the alternating layers of denser and less dense metal were produced by the sudden cooling.

Table III. B relates to the rod $(e) ; \delta_{1}, \delta_{2}, \delta_{3}$ have the same signification as in Table III $A$.

TABLE III. B.

\begin{tabular}{|c|c|c|c|}
\hline $\begin{array}{l}\text { Number of } \\
\text { observation. }\end{array}$ & $\delta_{1^{*}}$ & $\delta_{2}$ & $\delta_{3}$ \\
\hline $\begin{array}{r}1 . \ldots \ldots \\
3 . \ldots \ldots \\
7 \ldots \ldots . \\
11 . \ldots \ldots \\
17 . \ldots \ldots \\
20 . \ldots \ldots \\
23 .\end{array}$ & $\begin{array}{l}7.93 \\
7 \cdot 70 \\
7 \cdot 89 \\
7 \cdot 75 \\
7.64 \\
7.92\end{array}$ & $\begin{array}{l}7 \cdot 93 \\
7 \cdot 77 \\
7 \cdot 82 \\
7 \cdot 79 \\
7 \cdot 76 \\
7 \cdot 79\end{array}$ & $\begin{array}{l}7 \cdot 79 \\
7 \cdot 80 \\
7 \cdot 78 \\
7 \cdot 78 \\
7 \cdot 79 \\
7 \cdot 78\end{array}$ \\
\hline
\end{tabular}

We find, then, the slowly cooled bar possesses exactly similar variations in density as that cooled quickly in cold 
water ; whence it follows that they are not produced by the sudden cooling, but are to be regarded as indicating original want of homogeneity in the bar.

A comparison of $\delta_{2}$ with $\delta_{3}$ shows that the density of the portion of the bar dissolved away is only twice decidedly greater than that of the remaining portion. There is therefore no decrease of density from the surface towards the axis in the slowly cooled bar.

The foregoing experiments, taken together, therefore confirm the common belief that, in consequence of rapid cooling, a distribution of density results, in which the density decreases from the outside towards the centre.

I have so far spoken only of the distribution of density in a tempered steel bar. According to the usual view, snpported also by Mousson, not only the density, but also the hardness becomes smaller from the ontside towards the centre, so that a harder shell encloses a softer kernel.

During the gradual dissolving of the bars by acid, they were tested with a good file as to their hardness. All four bars showed themselves so hard through the entire substance - they were dissolved away so far that the remainder was only $\mathbf{1 . 5}$ millim. thick-that they could not be scratched by the file. The slowly cooled bar, on the contrary, was throughout very soft.

Although we must admit the possibility of the tempered bar being harder outside than inside, yet the assumption of a softer kernel enclosed by a harder shell is not proved, and would probably not be found to be the case in all steel bars of thickness less than those employed in these experiments.

Such bars therefore, whether cooled in warm or in cold water, must be regarded as homogeneous in respect of hardness.

It must remain for further experiments to decide whether this result holds good for still thicker bars, or how thick the bar may be, so that the interior shall remain soft in spite of tempering.

If we take this result together with that of the experiments upon density, we see that in tempered steel hardness and density do not go together, but that smaller hardness may correspond to greater density, and vice versâ. For, according to Table III. A, of seven layers removed from a steel bar four possessed a density consiclerably smaller than the mean density of the slowly cooled soft bar, and yet were quite hard. The same result is arrived at by observing that the outer layer of the bar (e), according to Table III. B, possessed a calculated density of 7.93 , and yet, in spite of the high density, was perfectly soft. 
Of the three consequences of a purely mechanical explanation of the processes involved in the hardening of steel by sudden cooling, that which relates to the distribution of density has been shown to be correct; the second, concerning the distribution of hardness, could not be demonstrated absolutely, although it is not to be concluded that it may not be correct for thicker bars; and the third, which requires an increase of volume produced by sudden cooling, corresponds, it is true, to the behaviour of most kinds of steel, but is strikingly contradicted by the behaviour of other kinds. The mechanical explanation in question assumes, lastly, a parallelism between density and hardness, since it explains an increase in hardness by an increase in density. We have seen, however, that density and hardness by no means increase or decrease together.

Hence we arrive at the conclusion that in the tempering of a steel bar, besides the mechanical, purely physical, process of sudden contraction, another change also, of chemical nature, takes place. This consists in a combination between the free carbon and the iron.

Barus* arrived at the same result some years ago, by means of other experiments and considerations. He considers the combination of carbon as the chief reason of hardness, which may, however, be somewhat modified by the mechanical process.

If, however, we inquire further into the reason of the combination of the carbon, we easily see that the reason can only be sought in the mechanical process, which appears then as the primary cause of hardening. It appears to me that it is essentially great pressures, produced by the sudden contraction of the red-hot steel plunged into cold water, which bring about the combination of the carbon and the iron.

This same idea has been already expressed in a paper published twenty years ago by Caron $\uparrow$. Experiments are there described which are concerned with the behaviour of suddenly cooled steel, of hammered steel, and of slowly cooled steel when treated with acids. The result obtained was that the residue of carbon was inappreciable in the first case, more considerable in the second case, and largest in the third case. Caron concludes from this that the steel hardened by sudden cooling contained its carbon almost altogether chemically, and that the change produced in the most complete manner by sudden cooling may be, partially at least, brought about by

* Wied. Ann. vii. p. 383 (1879).

$\uparrow$ Comptes Rendus, 1vi. pp. 45, 211 (1863). 
hammering. The reason of the combination of the carbon would, however, be the same in both cases-namely, the closer approximation of the molecules produced by pressure; and the smaller effect produced by hammering is explained by the fact that, in the first place, upon hammering the approximation takes place in one direction only, but upon cooling in all directions at once, and that, secondly, the pressures exerted are less intense than those produced by cooling.

If this view of the cause of the hardening of steel produced by sudden cooling be correct, it must also be possible to harden steel by allowing it to cool slowly from the red-hot condition, but so that during the cooling it is exposed to high pressure. Steel thus treated ought, then, like tempered steel, to contain more combined carbon, and to be hard. In fact, according to Clémandot* and Lan $\uparrow$, both of these conclusions are verified by experiment.

LV. Geometsical Methods in the Theory of Refraction at one or more Spherical Surfaces. By JaMES LOUDON, University College, Torontoł.

[Plate X.]

1. $\mathrm{N}$ cases of reflection or refraction at a spherical surface, 1 or a combination of spherical surfaces, or lenses, if $\mathrm{F}, \mathrm{F}^{\prime}$ be the primary and secondary principal foci of the surface, lens, or combination, and $\left(P, P^{\prime}\right),\left(R, R^{\prime}\right)$ pairs of conjugate points, it is known $(\$ 6)$ that

$$
\frac{f}{p}+\frac{f^{\prime}}{p^{\prime}}=1, \ldots . . . . . .
$$

where $f=\mathrm{RF}, p=\mathrm{RP}, f^{\prime}=\mathrm{R}^{\prime} \mathbf{\mathrm { T }}^{\prime}, p^{\prime}=\mathrm{R}^{\prime} \mathrm{P}^{\prime}$; and where the positive direction from $\mathrm{R}$ for $f$ and $p$ is opposite to, whilst that from $\mathrm{R}^{\prime}$ for $f^{\prime}$ and $p^{\prime}$ is the same as, the direction of the incident pencil.

Now since the relation (1) expresses the condition that the line $\frac{x}{p}+\frac{y}{p^{\prime}}=1$ passes through the point $\left(f, f^{\prime}\right)$, it follows that if the coincident lines FRR' $\mathrm{F}^{\prime}, \mathrm{FR}^{\prime} \mathrm{RF} \mathrm{F}^{\prime}$ be separated so that $R$ on the first axis coincides with $\mathbf{R}^{\prime}$ on the second, the line joining $\mathrm{P}$ on the former to $\mathrm{P}^{\prime}$ on the latter will always pass through the fixed point $\left(f, f^{\prime}\right)$. Hence we derive a geonse-

\footnotetext{
* Conptes Rendus, xciv, p. 703 (1882); xcv. p. 58 f (1882).

$\dagger$ Ibid. x civ. p. 952 (1882).

f Communicated by the Author.
} 